\title{
Article
}

\section{Youth Leisure-Time Physical Activity from the Perspectives of Young Adults with Visual Impairments}

\author{
Justin A. Haegele ${ }^{1 *}$
}

Received: 18 ${ }^{\text {th }}$ August, 2018; Accepted: $1^{\text {st }}$ December 2018; Published: $14^{\text {th }}$ January 2019

\begin{abstract}
The purpose of this study was to examine the meaning that young adults with visual impairments ascribe to their youth leisure-time physical activity experiences. This study adopted an interpretative phenomenological analysis (IPA) research approach. Ten participants (aged 21-34 years; eight women, two men) with visual impairments were included in this study. Semistructured, audio-taped telephone interviews acted as the primary source of data for this study. Data were analyzed thematically using a four-step process informed by IPA and three interrelated themes were constructed: (a) "I just always felt normal when I was doing them": Preferences for unstructured activities, (b) "They didn't baby me": Importance of supportive parents, and (c) "“They didn't know how to deal with my disability": Comparing stakeholders in integrated versus self-contained sport". The participants described a strong preference for unstructured physical activities and reported that support from parents was critical in allowing them to enjoy physical activities during youth.
\end{abstract}

Keywords: Blindness, Exercise, Phenomenological, Adapted Physical Activity

\section{Introduction}

Developing a physically active lifestyle at an early age can enhance health, help manage weight gain, and decrease the chances of developing chronic health conditions (e.g., cardiovascular disease, diabetes) throughout the lifespan (Centers for Disease Control and Prevention 2015; Jimenez-Pavon, Kelly, \& Reilly, 2010). Because of these health-related benefits, guidelines internationally recommend that youth engage in at least 60 minutes of moderate-to-vigorous physical activity, daily (US Department of Health and Human Services, 2008). Unfortunately, however, research indicates that school-aged individuals with visual impairments (that is, those with low vision and complete blindness) tend to be less physically active than their sighted peers (Augestad \& Jiang, 2015; Haegele \& Porretta, 2015; Kozub \& Oh, 2004), as well as those with other disabilities (Engel-Yeger \& HamedDaher, 2013; Longmuir \& Bar-Or, 2000; Williams et al., 2018), and are unlikely to meet recommended daily physical activity thresholds (Kozub, 2006; Wrzesinska, Lipert, Urzedowicz, \& Pawlicki, 2018). A lack of regular engagement in physical activity can place school-aged individuals with visual impairments at particular risk for developing chronic health conditions, such as obesity (Augestad \& Jiang, 2015). For example, Lieberman, Byrne, Mattern, Watt and Fernandez-Vivo (2010) found just $34.9 \%$ of a convenience sample of 152 youth with visual impairments to score within the healthy range of a body mass index assessment utilizing skinfold calipers.

Low levels of physical activity and the subsequent risk for developing health-related issues warrants a need for research examining why school-aged individuals with visual impairments are not engaging in physical activity. To date, most research in this area of inquiry has been concerned with parents' perspectives toward physical activity of their children with visual impairments (Columna, Fernandez-Vivo, Lieberman, \& Arndt, 2015; Columna, Dillon, Norris, Dolphin, \& McCabe, 2017; Perkins, Columna, Lieberman, \& Bailey, 2013; Ward, Fansworth, Babkes-Stellino, \& Perrett, 2011). Research in this area has demonstrated that parents value physical activity engagement for their children, and that preferred activities include those that are unstructured and integrated 
(Columna et al., 2015; 2017). However, a lack of well-planned opportunities to engage in physical activity clearly exists outside of the school-based physical education settings (Haegele \& Porretta, 2015; Perkins et al., 2013). When activities do exist, a number of barriers have been identified that can hinder physical activity engagement among this population. For example, parents have reported experiencing economic, familial and societal constraints that act as barriers to participation (Columna et al., 2015; 2017; Perkins et al., 2013). Furthermore, safety-related fears, concerns about insufficiently trained physical activity facilitators, and anxiety about stakeholders' understanding of disability can dissuade parents from encouraging their children with visual impairments from engaging in physical activities (Perkins et al., 2013; Ward et al., 2011).

While research in this area has typically focused on parental perspectives, examining physical activity experiences from the embodied perspectives of individuals with visual impairments themselves can provide additional insight into what influences them to be or not be active (Haegele \& Sutherland, 2015). Embodied perspectives are first person depictions of events, which take into consideration the interwoven nature of one's experiences in social events and their experience within their body (Ainley, 1989). Examining social events, such as physical activity engagement, from an embodied perspective asks researchers to break free from traditional mindsets of what we know and seek to understand what events would be like from another's viewpoint. By exploring physical activity from the embodied perspective of individuals with visual impairments, researchers can excavate personalized thoughts and feelings about physical activity experiences, as well as salient features that inform those thoughts and feelings, that contribute to physical activity engagement decisions (Haegele \& Sutherland, 2015; Spencer-Cavaliere \& Watkinson, 2010).

In recent years, research examining physical activity experiences from the embodied perspectives of individuals with visual impairments has focused primarily on experiences in schoolbased physical education (Alves, Haegele, \& Duarte, 2018; de Schipper, Lieberman, \& Moody, 2017; Haegele \& Kirk, 2018; Haegele \& Zhu, 2017; Haegele, Sato, Zhu, \& Avery, 2017; Haegele, Zhu, \& Davis, 2017; Lieberman, Robinson, \& Rollheiser, 2006). Several consistent findings emerge across this line of inquiry. For example, it is clear that perceptions of able and unable bodies are central to how individuals with visual impairments experience physical education and can inform experiences of belittlement and discriminations by stakeholders and peers (Haegele \& Kirk, 2018; Haegele \& Zhu, 2017). In addition, peer social interactions tend to be characterized as challenging or negative during physical education classes, regardless of educational setting (Haegele, Sato et al., 2017; Haegele, Zhu et al., 2017; Lieberman et al., 2006). Feelings of frustration and inadequacy experienced by individuals with visual impairments can influence them to self-select removal from physical education activities to engage in low-cost sedentary activities (Haegele \& Zhu, 2017).

While research in this area of inquiry is growing, few studies have focused on perspectives toward discretionary physical activity during leisure time, including community-based activities, family-based activities, or interscholastic or intramural school sport participation. One such study, conducted by Goodwin, Lieberman, Johnston, and Leo (2011), examined the social meaning that school-aged individuals with visual impairments ascribed to experiences at a one-week residential summer sports camp, and described the shared emotional connections that surfaced between participants. More recently, Haegele, Yessick and Kirk (2017) explored the physical activity experiences of four youth with visual impairments living in Alaska, who described preferences for unstructured activities and the importance of physical activity engagement with family members. It is clear that understanding how individuals with visual impairments experience leisure-time physical activity can provide important insight into why they choose to engage or not to engage in activities. Subsequently, insights can be used to develop and promote physical activity opportunities that are designed to meet needs expressed specifically from the perspectives of those with visual impairments. However, the extant literature is limited to just a few studies that focus on specific settings (residential sport camps) and geographic regions (Alaska) and are not easily transferable to the experiences of other individuals with visual impairments (Goodwin et al., 2011; Haegele, Yessick et al., 2017). 
It is apparent that more research is needed to look outside of the physical education context and expand our understanding of the embodied perspectives of individuals with visual impairments in discretionary, leisure-time physical activity. Thus, the purpose of this study was to examine the meaning that individuals with visual impairments ascribe to their youth leisure-time physical activity experiences. This study was retrospective in nature, where young adult participants recalled their experiences as youth ( $<18$ years of age). Utilizing this methodology allowed the researcher to examine experiences entirely without the danger of influencing those experiences as an outsider (Paechter, 2012). In addition, the retrospective nature of the study permitted participants to have gained some emotional distance from events that can be challenging to discuss when being interviewed (Haegele \& Zhu, 2017).

\section{Methods}

\section{Research Approach}

To explore the participants' experiences in physical activity as youth, an interpretative phenomenological analysis (IPA) research approach was adopted (Smith, 2017; Smith, Flowers, \& Larkin, 2013). Simply put, IPA is "a qualitative approach concerned with examining personal lived experience" (Smith, 2017; p. 219). IPA is concerned with examining how participants make sense of their personal and social worlds, and excavating the meaning that particular experiences hold for them (Smith et al., 2013; Smith \& Osborn, 2008). Utilizing this approach, researchers attempt to gain an understanding of experiences as lived processes that are unique to each person's embodied relationship with the world (Smith et al., 2013). IPA draws from three theoretical touchstones: phenomenology, hermeneutics, and ideography. IPA is phenomenological, in that it is concerned with examining participants' personal and embodied accounts of experiences, as opposed to objective descriptions of events (Smith, 2017; Smith et al., 2013). Thus, researchers must attempt to understand each participant's world and describe what it is like while focusing on specific experiences (Larkin et al., 2006). IPA research centralizes on a double hermeneutic of interpretation, where the role of the data analyst is to "make sense of the participant making sense" of their personal experiences with the world (Smith, 2019; p.219). Lastly, a hallmark of IPA is its idiographic roots, in that it is concerned with understanding the experience of each individual participant, in detail. This informs several important features that are common to IPA studies, such as small sample sizes and the aim to highlight how experiences and meaning reveal themselves for particular individuals on a case level. This feature of IPA conflicts with most nomothetic research approaches that aim to generalize experiences about groups or populations (Smith, 2017; Smith et al., 2013).

\section{Participants}

Individuals were purposively recruited for this study via an electronic call for participants. The electronic call was distributed through listservs for individuals with visual impairments that are managed by two organizations in North America. Prior to dissemination, the author contacted the organizations and obtained permission to distribute the research call to their members. The call for participants included information related to the purpose, time commitment, eligibility criteria, and incentive for completion (\$20.00 USD gift card) for this study. Eligibility criteria for this study included individuals who (a) identified as having a visual impairment during their youth $(<18$ years of age); (b) were 18 years or older, but less than 36 years of age and (c) would be willing to complete a telephone interview with the researcher for 60-90 minutes. Interested individuals were asked to contact the author via email, and to answer a brief screening questionnaire to ensure they met the eligibility criteria. Those who met these criteria were invited to participate in telephone interviews. The author's university institutional review board reviewed and approved of all study procedures.

Ten participants (aged 21-34 years; eight women, two men) successfully completed interviews and were included in this study. Nine participants were residents of the United States, and one was a resident of Canada. Of the ten participants, eight self-identified their race and/or ethnicity as Caucasian, one as Indian-American, and one as Hispanic. Seven participants reported having 
congenital visual impairments, whereas three reported losing their vision before the age of two. Table 1 provides participants' demographic information and additional details about each participant's visual impairment during youth. Each participant consented to participate in this study, and pseudonyms were assigned to participants to protect identity.

Table 1. Demographic descriptors of participants

\begin{tabular}{|c|c|c|c|c|c|}
\hline Name & Age & Gender & Race/Ethnicity ${ }^{a}$ & Age of VI & $\begin{array}{c}\text { Description of VI During } \\
\text { Youth }\end{array}$ \\
\hline Abby & 31 & Female & Caucasian & Congenital & Complete blindness ${ }^{\mathrm{b}}$. \\
\hline Bailey & 32 & Female & Caucasian & Congenital & $\begin{array}{l}\text { Monocular vision with } 20 / 200 \\
\text { visual acuity during the day } \\
\text { in her left eye; complete } \\
\text { blindness in her right eye. }\end{array}$ \\
\hline Claire & 29 & Female & Caucasian & 2 years & $\begin{array}{l}\text { Low vision ; } \text {; visual acuity } \\
\text { ranged from 20/200 to 20/400 } \\
\text { during youth. Slightly } \\
\text { reduced peripheral vision. }\end{array}$ \\
\hline Daya & 34 & Female & $\begin{array}{l}\text { Indian- } \\
\text { American }\end{array}$ & 2 years & $\begin{array}{l}\text { Minimal light perception }{ }^{\mathrm{d}} \text { in } \\
\text { her left eye; complete } \\
\text { blindness in her right eye. }\end{array}$ \\
\hline Frankie & 21 & Female & Caucasian & Congenital & Complete blindness. \\
\hline Julie & 21 & Female & Caucasian & Congenital & Complete blindness. \\
\hline Lisa & 21 & Female & Caucasian & 9 months & Low/partial vision. \\
\hline Matthew & 32 & Male & Caucasian & Congenital & $\begin{array}{l}\text { Low vision; vision loss } \\
\text { progressed throughout youth. }\end{array}$ \\
\hline Nate & 27 & Male & Caucasian & Congenital & Complete blindness. \\
\hline Rosario & 26 & Female & Hispanic & Congenital & Minimal light perception. \\
\hline
\end{tabular}

Notes. VI=visual impairment; aparticipants self-identified their race and/or ethnicity in an open-ended question. bComplete blindness is the complete lack of light and form perception. clow vision refers to uncorrectable vision loss that interferes with daily activities. cLight perception is the ability to perceive the presence or absence of light.

\section{Data Collection}

Two sources of data were utilized in this study: interviews and reflective interview notes. Semistructured, audio-taped telephone interviews completed by the author acted as the primary source of data for this study. The utilization of telephone interviews may be considered a limitation because of the inherent inability to record facial gestures or body language during interviews (Goodwin \& Staples, 2005). However, telephone interviews were utilized in this study, in lieu of face-to-face interviews, because of several advantageous characteristics. More specifically, telephone interviews: (a) are considered cost-effective, (b) can reduce interviewer effects, and (c) permit researchers to sample participants from a vast geographic area (Goodwin \& Staples, 2005; Haegele \& Zhu, 2017). Interviews ranged from 55 to 75 minutes in length and assumed a conversational tone. All procedures were reviewed and approved by the author's college human subjects committee, and informed consent was obtained from the participants.

Each interview session began with the author describing the purpose of the study, the time commitment of the interview, and his personal background to expose his positionality as an interviewer. More specifically, he stated that (a) he was a male who does not identify as having a disability, (b) he was a faculty member in a physical education teacher education program at a research institution, (c) he had previous experience directing sports-related programming for youth with visual impairments, and (d) his research focuses primarily on understanding experiences of 
individuals with visual impairments in physical activity contexts. By describing his positionality, the interviewer explicated his relationship with the group that was being studied, and exposed any potential biases to the interviewee that may have been rooted in his previous positions and experiences. This process helped publicize how the researcher's positionality (in terms of gender, disability status, and work experience) influenced the data being collected and thus the information that is garnered from this study (Rose, 1997). Interviews followed an interview guide, which was developed by Haegele, Zhu et al. (2017), to ensure that a similar line of inquiry was pursued across all participants. The original version of the interview guide focused on examining physical education experiences (Haegele, Zhu et al., 2017), therefore questions were modified to center on leisure-time physical activity experiences to fit the purpose of the current study. The interviewer was mindful to use the guide flexibly and to allow the interviewee to dictate the magnitude of each discussed topic (Smith, 2017). In this way, the interview guide was utilized as a stimulus to help facilitate discussion, rather than a prescription for the conversation. Participants were asked to reflect on their experiences in leisure-time physical activity outside of required physical education classes; however, they were not directed toward any specific type of activities. Thus, participants were free to describe experiences in family-based, community-based, or school-based (e.g., afterschool sport) activities that were most meaningful, impactful, or memorable from their youth. Example questions include: (a) can you tell me about your experiences in physical activity outside of physical education as a youth?; (b) how meaningful were these activities to you?; and (c) how did you feel about the physical activities you engaged in?

Reflective interview notes, which included initial feelings about the tone and ease of the conversation and exceptionally meaningful items of interest expressed during the conversation (Smith \& Sparkes, 2017), were recorded by the interviewer during and after each interview session. The reflective note taking process allowed the interviewer to record any potential personal biases that may have affected the interview and interpretation of the interview. In this way, the researcher looked 'inward' toward his identity, while also looking 'outward' to his relation with the research and the interview process (Rose, 1997). This process supported interviewer reflexivity by allowing the researcher to conceptually return to the interview setting during analysis and critically reflect on the conversation (Walker, Reid, \& Priest, 2013).

\section{Data Analysis}

After data collection, a graduate assistant transcribed the audiotaped interviews verbatim. Because IPA focuses on interpreting the content of experiences, interview transcripts included all words spoken by the interviewer and interviewee, but did not include detailed accounts of nonverbal utterances or conversational pauses (Smith, 2017; Smith et al., 2013). Following transcription, data were analyzed thematically by the author (analyst) using a four-step process informed by IPA. According to Smith (2017), the aim of this process is to "gain a detailed and personalized understanding of the psychological experience of a phenomenon" (p.222). First, the analyst read and reread each participant's transcript and reflective field notes a number of times to develop a deep and intimate understanding of the content (Smith, 2017). During this process, the analyst highlighted items of interest and recorded interpretative commentary in the data sources in the form of descriptive and exploratory comments. Second, the analyst reduced each participant's individual data (i.e., interview transcripts and reflective field notes) and relevant interpretative commentary into emergent themes (Smith, 2017; Smith et al., 2013). The objective of this process was to construct thematic statements that were specific, dynamic, and grounded in what the respondent said during the interview, while also including distilled and abstracted thought (Smith, 2017). Thus, themes began to "reflect not only the participant's original words and thoughts but also the analysts' interpretation" (Smith et al., 2013, p.92). Third, constructed themes were compared within each participant's documents to establish coherent inductive thematic clusters. At this point, all steps were completed independently at the case level. The final step was to search for patterns of convergence and divergence across the corpus of participants through constant comparison. After themes were identified across participants, they were reviewed to ensure they aligned with the purpose of the 
study and adopted research approach. Thematic clusters that were considered in line with the purpose and research approach were summarized and presented as results.

\section{Quality Assessment}

Four principles of assessing quality of qualitative research, presented by Yardley (2000) and recommended by Smith et al. (2013) for use in IPA studies, were followed to evaluate this study. The interviewer explicating potential biases to participants by describing his positionality during the interview process addressed the first principle, sensitivity to context. This principle was also addressed with the inclusion of an abundant number of verbatim transcript extracts in the presentation of the results (Smith et al., 2013). The second principle, commitment and rigor, was addressed through the selection of a corpus of participants which aligned with the purpose of the study and by utilizing a previously established interview guide (Haegele, Zhu et al., 2017) that had been modified to address the purpose of the current study (Smith et al., 2013). The inclusion of explicit descriptions of the participant recruitment, interview, transcription, and analysis procedures supported the third principle, transparency and coherence. This principle was further supported through accounting for researcher positionality, reflexivity, and biases during the research process. Lastly, the fourth principle of assessing quality of qualitative research, impact and importance, lies in whether the research communicates important and relevant findings. Although the researcher values this line of research, the work presented here will ultimately be judged by those consuming it.

\section{Results and Discussion}

Based on the data analysis, three interrelated themes were constructed from the transcripts and reflective field notes: (a) "I just always felt normal when I was doing them": Preferences for unstructured activities, (b) "They didn't baby me": Importance of supportive parents, and (c) "They didn't know how to deal with my disability": Comparing stakeholders in integrated versus selfcontained sport. The three themes are described, exemplified, and interpreted within the context of the current literature below.

\section{"I Just Always Felt Normal When I was Doing Them": Preferences for Unstructured Activities}

When describing their experiences in discretionary, leisure-time physical activity during their youth, most participants explained a preference for engaging in unstructured and informal physical activities rather than organized sports (e.g., afterschool sports, community-based recreation programs). Among the most popular activities among the participants were swimming (Abby, Lisa, Daya), hiking/walking (Bailey, Nate, Claire), bicycling (Lisa, Nate), or simply playing active games such as tag (Abby, Bailey, Daya). Interestingly, these activities paralleled those that are preferred among parents of children with visual impairments (Columna et al., 2017) as well as those that have been reported as the most popular among adult populations with visual impairments (Jaarsma, Dekker, Koopsmans, Dijkstra, \& Geertzen, 2014). The participants noted several characteristics of unstructured and informal activities that made them appealing. For example, Bailey described appreciating the lack of pressure to participate that characterized her experiences:

I enjoyed the dynamic of [unstructured activities], because I felt like there was no pressure. No one cared what happened. If I didn't want to participate, if I wasn't feeling well, I'd say 'hey guys, I'm just going to hang out on the side and watch.' One of them [friends] might come over and hang out with me, but there wasn't that pressure to fully engage all the time every day and try to meet someone's expectations [like there was in structured activities or physical education]. I could just do what I wanted, and I really liked that.

Similarly, Daya noted that the lack of formal rules and subsequent flexibility associated with unstructured activities were preferable: 
When you're engaging in unstructured activities, you can modulate what you're playing and the intensity of it. You can regulate activities to suit you. There's all these rules [with structured activities], I can't break a rule, this person has this specific rule, I need to have this specific rule. When rules are flexible [with unstructured games], it just made it so much easier for me to find my niche and create a role I was comfortable in.

The availability of adaptations and modifications to activities has been reported as desirable among youth with visual impairments when engaging in leisure-time physical activity (de Schipper et al., 2017). Thus, participants' perspectives about the importance of flexibility and the lack of pressure to participate are not surprising. The finding that youth with visual impairments prefer unstructured physical activities over structured sport is consistent with those found by Haegele, Yessick et al (2017) when examining the perspectives of Alaskan youth, and extends these findings to a larger context. A preference for unstructured play may be particularly important for contributing to overall physical activity engagement of youth with visual impairments because of the commonly accepted lack of structured activities that exists outside of school settings (Haegele \& Porretta, 2015).

Socialization experiences were particularly meaningful in contributing the participants' preferences of unstructured physical activities. It is known that social interactions during structured school-based physical activities (e.g., physical education) between youth with disabilities and typically developing peers tend to be stressful or negative (Haegele, Sato et al. 2017; Haegele, Zhu et al. 2017; Lieberman et al. 2006). For example, in research by Orr, Tamminen, Sweet, Tomasone, and Arbour-Nicitopoulos (2018), youth with physical disabilities described being alienated and treated as an "other" by their peers during structured team sport activities. Experiences like these can lead youth with disabilities to develop negative perceptions about their ability to engage in team sport activities and disengage from physical activity (Haegele \& Zhu, 2017; Orr et al., 2018). The participants in the current study also experienced social issues with structured team sport activities [reflective interview notes], but fortunately found contrasting experiences with unstructured activities. According to the participants, unstructured physical activities provided a forum to enjoy meaningful social interactions with peers. This finding is consistent with research pertaining to children without disabilities, that suggests that unstructured physical activity settings play an important role in encouraing social behaviors by facilitating group play and reducing physical isolation (Mayfield et al., 2017). Most notably, participants reported feeling "happy and included" (Lisa) during unstructured activities, and that unstructured activities were "kind of the most normal part of my childhood, because I had friends that I could just go out and play with" (Rosario). Furthermore, Bailey recalled that she "had no reservations" during unstructured activities with her neighborhood peers, because "no one had anything negative to say to me about participating." Congruently, Abby reported that:

I just always felt normal when I was doing them [unstructured physical activities]. I felt like a real person that can do something. I felt in control, like I can control my path and what I did. Yeah, I felt normal. I felt like my vision loss went away, and like I was a whole person. I felt included, like they [peers] didn't see me as being any different, just one of them. Just the less structured aspect. People wanted to do it with me rather than being forced to do it a certain way. It was just so natural.

Clearly, engaging in unstructured physical activities allowed Abby a sense of "fitting in", which she was able to clearly articulate years later. Several other participants noted similar experiences engaging in unstructured physical activities with their peers, noting that "I was just one of them" (Bailey), "There was nothing that really held me back socially [during unstructured activities]" (Julie), and "I don't think it was any different for me than it was for my sighted friends. We all contributed and played along" (Claire). Participants described "loving" (Rosario) these unstructured activities and associated feelings of happiness and pride were their active participation [reflective interview notes]. These findings are consistent with research, which has identified "feeling normal" and "fitting 
in" as critical motivators that can help provoke youth with disabilities to engage in physical activity (Newitt, Barnett, \& Crowe, 2015).

\section{“They Didn't Baby Me": Importance of Supportive Parents}

When describing factors that influenced physical activity engagement, the participants overwhelmingly referred to family support as being essential. For one participant, Frankie, the lack of family support that she received discouraged her from engaging in much leisure-time physical activity, particularly during adolescence. She noted that:

I wasn't allowed to go to any sport-related games or camps. I used to play with my brothers when I was very little, but my parents put a stop to that because I was becoming a girl. I was annoyed. It was mostly my stepfather and I didn't argue with him. I didn't understand what the issue was at the time. I felt like he was stopping it for no reason and it was silly and I missed playing with the boys.

Frankie recalled being discouraged from engaging in physical activity, and attributed this dissuasion to "common sense" gender ideals (Azzarito \& Solomon, 2009) held by her stepfather. Based on Frankie's commentary, it appeared that cultural gender ideals informed her stepfather's opinion of the types of activities she should be participating in while "becoming a girl". Research suggests that girls may experience complex relationships with physical activity in instances like this, where they feel pressure to appear feminine and act accordingly, limiting their physical activity engagement (Spencer, Rehman, \& Kirk, 2015). Frankie's experiences may provide a valuable example of how bodies with disabilities are also gendered bodies (Flintoff, Fitzgerald, \& Scraton, 2008), and how one's gender identify and identity as an individual with a visual impairment can intersect to inform experiences in sporting cultures, such as physical activity (Haegele \& Kirk, 2018).

Fortunately, Frankie's experiences were unique in this study, and each of the other participants described how having supportive and encouraging parents promoted physical activity engagement for them during youth. Participants reported that "they [parents] encouraged me to stay physically fit and active" (Matthew), "my parents never limited me, they always let me do whatever I wanted, within reason" (Julie), "they [parents] let me do what I wanted and they treated me like any other regular kid. They didn't baby me" (Abby) and "my parents knew not to over support by sitting there and doing everything and hovering" (Daya). Nate, who spoke at length about how supportive his father and grandfather were, recalled:

There wasn't any 'you're blind, you can't do this'. Rather, my grandfather would say 'if you want to do this, let's figure out how to do this successfully'. These were bond-building experiences. It definitely counteracted the idea that I couldn't do things because I' $m$ blind. They [father and grandfather] never really told me no. It was like if other kids were going to do it, we would find a way for me to do it as well. They never had the preconceived notion that 'I couldn't.'

Nate suggested that much of his family's attitude toward his abilities were informed by experiences of his father, who also had a visual impairment. He noted that "they [father and grandfather] were prepared and ready to help me do whatever I needed to enjoy the world" because "I guess I was lucky since my dad is also visually impaired and they have been dealing with this since the 50's." The participants reported feeling empowered to be active because of their parental support, and enjoyed that there was a lack of sympathy for them from their parents [reflective interview notes]. These results affirm previous assertions about the importance of having support from family members to promote physical activity engagement among individuals with visual impairments (Jaarsma et al., 2014). Further, this research extends previous findings by depicting first person narratives of the influence of parental support on physical activity during youth.

While research has demonstrated that parents of children with visual impairments tend to value physical activity engagement (Ward et al., 2011), safety-related concerns tend to dissuade parents 
from encouraging their children to be active (Perkins et al., 2013). Safety concerns, like these, have also emerged in narratives about school-based physical education, where individuals with visual impairments have expressed feeling less encouraged to participate because safety needs were not met (Haegele \& Kirk, 2018). The participants in this study acknowledged that safety was a consideration; however, it did not impede their parents from encouraging activity. For example, participants reported that "I liked that I could just go off and do whatever, and if I got hurt it was like 'yeah, you're fine, you'll get better' from my parents" (Claire), "they wanted me to be safe but they didn't want to tell me no if they didn't need to" (Julie), and "although my dad would get nervous, my mom would be like 'let her do it, she needs to do it' [when talking about physical activity]" (Daya). Lisa explained that there was value in her parents not being overly concerned with safety:

I'd be on my bike and I'd hit a crack and fall, and my knee was bleeding and my parents would just give me a Band-Aid. They would just say 'alright, you're fine. Get out of here.' I think it just helped me to realize that during things like physical activity, I might get a few more bumps and bruises and stuff than the average person. But, that doesn't mean I should let having a disability stop me from being active.

While safety-related fears have been explained as a potential barrier to physical activity for youth with visual impairments (Perkins et al., 2013), the current study provides a depiction of the value of supportive parents who quelled concerns of safety. Regarding safety and physical activity, Matthew recalled a quote from one of his parents, who stated "blindness cannot hold you back, live the life that you want."

\section{"They Didn't Know How to Deal with My Disability": Comparing Stakeholders in Integrated versus Self-Contained Sport}

While the participants described being well-supported by their parents and an affinity for unstructured physical activities, several also recalled attempting to engage in integrated organized sport (e.g., community-based sport, interscholastic sport) during their youth. According to the participants' narratives, these attempts were typified by unpleasant or belittling interactions with coaches and other stakeholders. For example, Rosario recalled an instance where her coach saw her not participating in a drill, and decided to attempt to physically prompt her through an activity without consent:

All of a sudden, I had someone in my face who was moving my body. If I'm not doing something correctly, I expect to be moved. But, it's one thing to say 'hey can I walk you through how to do this' and another to just suddenly have hands on you without consent. Maybe he was tired of me standing in the corner like a stone because I'm sure that was off putting. I just couldn't think or really move around with all the noise in the room. I was pretty much frozen and curled into a mental ball.

The use of physical guidance (e.g., the physical placement of a student's body through a movement) to model activities can help youth who are blind comprehend skills or activities being taught. However, doing so without first asking the student for consent can be a belittling experience that can lead to discomfort and further withdrawal from activities ( $\mathrm{O}^{\prime}$ Connell, Lieberman, \& Petersen, 2006). Like Rosario, Abby recalled that it seemed that her coaches were insufficiently trained to work with individuals with visual impairments. She noted that:

Didn't like the feeling of being excluded from different things. I thought it would have been cool to have been given that opportunity. They just didn't know how to deal with my disability. It was a matter of them not knowing what to do.

Insufficient training of stakeholders is listed by parents of children with visual impairments as a influential barrier that dissuades them from engaging their child in physical activity (Perkins et al., 2013). While some participants expressed that they "just can't let it [issues with stakeholders] stop 
you" (Daya), it was clear that the participants as a whole did not feel supported when engaging in structured integrated activities with their sighted peers.

Fortunately, while the participants struggled to engage in integrated sport opportunities, a number of participants explained the value of participating in organized sport or physical activity specifically designed for youth with visual impairments. Participants reported participating in a variety of types of camps, sport teams (e.g., goalball teams), or lessons (e.g., horseback riding lessons) throughout their youth that were serviced by the 'blind community.' When discussing these activities, participants recalled "I felt like I was an equal and I could participate fully. I could just be a normal kid" (Bailey) and "at camp, everyone had a vision loss of some sort so, we all felt normal. We all just felt like kids and not having to focus on it" (Abby). Rosario explained further that:

I started doing more camps with and for the blind and began getting along with more peers that way. In a sense, I feel like the activities at those camps were very important for me. I

felt like the activities, like horseback riding and tandem cycling, were about me. It was also a good time for social interaction. Because we were all blind, even though things took so much longer, it was more of a hands-on kind of approach and we got a lot more done [than in school-based physical education].

Although parents of children with visual impairments typically prefer integrated activities with peers without disabilities (Columna et al., 2015; 2017), it was clear that the participants in this study recalled positive memories of activities that were self-contained in the blind community. When describing his experiences with activities in the blind community, Nate was outspoken about the importance of current youth getting the opportunity to participate in these types of activities. He stated that:

There are many people whose parents stick them in a room because they can't see and that's why they grew up thinking that they can't do anything. Their parents never gave them the ability to try. It's sad.

Based on the participants narratives, it is clear that their experiences in self-contained activities provided important opportunities for self-growth. These experiences conflicted with belittling or exclusionary experiences with integrated community-based sport or physical activities, which seemed to be driven by perceptions of able and unable bodies of stakeholders (Haegele \& Kirk, 2018; Haegele \& Zhu, 2017).

\section{Limitations and Conclusions}

The purpose of this study was to examine the meaning that individuals with visual impairments ascribe to their youth leisure-time physical activity experiences. Several characteristics of this study may be considered limitations. Primarily, the retrospective nature of this study may be considered a limitation, as participants were asked to recall their experiences during youth. While benefits of this approach have been discussed, it is possible that meaningful particularities of the participants' physical activity experiences may have been lost because of the nature of the recall questions (Bredahl, 2013). However, as suggested by Bredahl (2013), the objective of phenomenological work is to present general critical issues centered specifically on each participants' subjective experiences. In addition, because of the consistently changing landscape of physical activity for individuals with visual impairments, it is likely that the participants' recollections of their physical activity engagement as youth do not reflect the current status of physical activity for youth with visual impairments today. Rather, these reflections are intended to only represent the meaning that these particular adults ascribed to their personal experiences.

Youth with visual impairments tend to engage in less physical activity than their sighted peers (Augestad \& Jiang, 2015; Haegele \& Porretta, 2015). However, little previous attention has been given to understanding youth physical activity engagement from the embodied perspectives of those with visual impairments. Utilizing an IPA approach, three interrelated themes were constructed that contribute to our understanding of how individuals with visual impairments experience leisure-time 
discretionary physical activity during youth. The three themes add unique insights to the extant literature. Generally, the participants described a strong preference for unstructured physical activities because of the inherent flexibility. In addition, participants reported that support from their parents were critical in allowing them to enjoy physical activity during their youth. Unfortunately, however, instances of frustration and belittlement typified experiences in structured, integrated community-based physical activity. Cumulatively, the participants were positive and enthusiastic about their discretionary, leisure-time physical activity as youth, which conflicts with previous findings about experiences in structured, school-based physical education (Haegele \& Kirk, 2018; Haegele \& Zhu, 2017). Thus, characteristics of these unstructured leisure-time physical activities may be adopted by those providing physical activity opportunities, be that school-based, communitybased, or family-based, to better meet the needs of students with visual impairments.

\section{Perspectives}

Recently, attention has shifted to value the embodied perspectives of individuals with disabilities regarding their experiences in physical activity (Haegele \& Sutherland, 2015). Examining social events, like physical activity engagement, from an embodied perspective allows researchers to gain an understanding of the personalized meaning of events from the viewpoint of those with disabilities. Although this area has gained attention, little has been done to explore the perspectives of those with visual impairments toward leisure-time physical activity. Utilizing an IPA approach, three themes were uncovered in this study that describe salient features of physical activity as well as how these features were experienced from the perspectives of those with visual impairments. The features described positively and enthusiastically by the participants provide critical exemplars that can be adopted by those interested in providing physical activity programming for similar populations. These exemplars may be particularly meaning for application in school-based physical education settings, where persons with visual impairments have often reported discriminatory and discouraging experiences (Haegele \& Zhu, 2017).

Author Correspondence:

1 Old Dominion University; jhaegele@odu.edu

* Correspondence: jhaegele@odu.edu; Tel.: +01-757-683-5338

Funding: This research received no external funding

Conflicts of Interest: The authors declare no conflict of interest.

\section{References}

Alves, M.L., Haegele, J.A., \& Duarte, E. (2018). “We can't do anything”: The experiences of students with visual impairments in physical education in Brazil. British Journal of Visual Impairment, 36(2), 152-162. doi:10.1177/02646196617752761

Ainley, S.C. (1989). Day brought back from night: Aging and new vision loss. London, UK: Routledge.

Augestad, L.B., \& Jiang, L. (2015). Physical activity, physical fitness, and body composition among children and young adults with visual impairments: A systematic review. British Journal of Visual Impairment, 33(3), 167182. doi: $10.1177 / 0264619615599813$

Azzarito, L., \& Solomon, M. (2005). A reconceptualization of physical education: The intersection of gender/race/social class. Sport, Education, \& Society, 10(1), 25-47. doi:10.1080/1357332052000028794

Bredahl, A-M. (2013). Sitting and watching the others being active: The experienced difficulties of PE when having a disability. Adapted Physical Activity Quarterly, 30, 40-58.

Centers for Disease Control and Prevention. (2015). Physical activity and health. Retrieved from https://www.cdc.gov/physicalactivity/basics/pa-health/index.htm.

Columna, L., Dillon, S.R., Norris, M.L., Dolphin, M., \& McCabe, L. (2017). Parents' perceptions of physical activity experiences for their families and children with visual impairments. British Journal of Visual Impairment, 35(2), 88-102. doi:10.1177/0264619617691081

Columna, L., Fernandez-Vivo, M., Lieberman, L., \& Arndt, K. (2015). Recreational physical activity experiences among Guatemalan families with children with visual impairments. Journal of Physical Activity \& Health, 12(8), 1119-1127. 
de Schipper, T., Lieberman, L., \& Moody, B. (2017). “Kids like me, we go lightly on the head": Experiences of children with visual impairment on the physical self-concept. British Journal of Visual Impairment, 35(1), 5568.

Engel-Yeger, B., \& Hamed-Daher, S. (2013). Comparing participation in out of school activities between children with visual impairments, children with hearing impairments and typical peers. Research in Developmental Disabilities, 34(10), 3124-3132. doi:10.1016/j.ridd.2013.05.049

Flintoff, A., Fitzgerald, H., \& Scraton, S. (2008). The challenges of intersectionality: Researching difference in physical education. International Studies in Sociology of Education, 18(2), 73-85.

Goodwin, D.L., Lieberman, L.J., Johnston, K., \& Leo, J. (2011). Connecting through summer camp: Youth with visual impairments find a sense of community. Adapted Physical Activity Quarterly, 28(1), 40-55.

Goodwin, D.L., \& Staples, K. (2005). The meaning of summer camp experiences to youth with disabilities. Adapted Physical Activity Quarterly, 22(2), 159-177.

Haegele, J.A., \& Kirk, T.N. (2018). Experiences in physical education: Exploring the intersection of visual impairment and maleness. Adapted Physical Activity Quarterly, 35(2), 196-213. doi:10.1123/apaq.2017-0132

Haegele, J.A., \& Porretta, D.L. (2015). Physical activity and school-age individuals with visual impairments: A literature review. Adapted Physical Activity Quarterly, 32(1), 68-82. doi:10.1123/apaq.2013-0110

Haegele, J.A., Sato, T., Zhu, X., \& Avery, T. (2017). Physical education experiences at residential schools for students who are blind: A phenomenological inquiry. Journal of Visual Impairment E Blindness, 111, 135-147.

Haegele, J.A., \& Sutherland, S. (2015). The perspective of students with disabilities toward physical education: A review of qualitative inquiry. Quest, 67(3): 255-273. doi:10.1080/00336297.2015.105118

Haegele, J.A., Yessick, A., \& Kirk, T.N. (2017). Physical activity experiences of youth with visual impairments: An Alaskan perspective. British Journal of Visual Impairment, 35(2), 103-112. doi:10.1177/0264619616685376

Haegele, J.A., \& Zhu, X. (2017). Experiences of individuals with visual impairments in integrated physical education: A retrospective study. Research Quarterly for Exercise $\mathcal{E}$ Sport, 88(4), 425-435. doi:10.1080/02701367.2017.1346781

Haegele, J.A., Zhu, X., \& Davis, S. (2017). The meaning of physical education and sport among elite athletes with visual impairments. European Physical Education Review, 23(4), 375-391. doi:10.1177/1356336X16650122

Jaarsma, E.A., Dekker, R., Koopmans, S.A., Dijkstra, P.U., \& Geertzen, J.H.B. (2014). Barriers and facilitators of sport participation in people with visual impairments. Adapted Physical Activity Quarterly, 31, $240-264$. doi:10.1123/apaq.2013-0119

Jimenez-Pavon, D., Kelly, J., \& Reilly, J. (2010). Associations between objectively measured habitual physical activity and adiposity in children and adolescents: Systematic review. International Journal of Pediatric Obesity, 5(1), 3-8.

Kozub, F.M. (2006). Motivation and physical activity in adolescents with visual impairments. Rehabilitation and Education for Blindness and Visual Impairment, 37, 149-160.

Kozub, F.M., \& Oh, H. (2004). An exploratory study of physical activity levels of children and adolescents with visual impairments. Clinical Kinesiology, 58(3), 1-7.

Larkin, M., Watts, S., \& Clifton, E. (2006). Giving voice and making sense in interpretative phenomenological analysis. Qualitative Research in Psychology, 3, 102-120. doi:10.1191/1478088706qp062oa

Lieberman, L.J., Byrne, H., Mattern, C., Watt, C., \& Fernandez-Vivo, M. (2010). Health-related fitness of youths with visual impairments. Journal of Visual Impairment \& Blindness, 104(6), 349-359.

Lieberman, L.J., Robinson, B.L., \& Rollheiser, H. (2006). Youth with visual impairments: Experiences in general physical education. Rehabilitation and Education for Blindness and Visual Impairment, 38(1), 35-48.

Longmuir, P.E., \& Bar-Or, O. (2000). Factors influencing physical activity levels of youth with physical and sensory disabilities. Adapted Physical Activity Quarterly, 17(1), 40-53.

Mayfield, C.A., Child, S., Weaver, R.G., Zarrett, N., Beets, M.W., \& Moore, J.B. (2017). Effectiveness of a playground intervention for antisocial, prosocial, and physical activity behaviors. Journal of School Health, 87(5), 338-345.

Newitt, R., Barnett, F., \& Crowe, M. (2015). Understanding factors that influence participation in physical activity among person with neuromusculoskeletal conditions: A review of qualitative studies. Disability $\mathcal{E}$ Rehabilitation, 38(1), 1-10. doi:10.3109/09638288.2014.996676

O'Connell, M., Lieberman, L.J., \& Petersen, S. (2006). The use of tactile modeling and physical guidance as instructional strategies in physical activity for children who are blind. Journal of Visual Impairment $\mathcal{E}$ Blindness, 100(8), 471-477.

Orr, K., Tamminen, K.A., Sweet, S.N., Tomasone, J.R., \& Arbour-Nicitopoulos, K.P. (2018). "I've had bad experiences with team sport": Sport participation, peer need-thwarting, and need-supporting behaviors among youth identifying with physical disability. Adapted Physical Activity Quarterly, 35(1), 36-56. doi:10.1123/apaq.2017-0028 
Paechter, C. (2012). Researching sensitive issues online: Implications of a hybrid insider/ outsider position in a retrospective ethnographic study. Qualitative Research, 13(1), 71-86. doi:10.1177/1468794112446107

Perkins, K., Columna, L., Lieberman, L., \& Bailey, J. (2013). Parents' perceptions of physical activity for their children with visual impairments. Journal of Visual Impairment $\mathcal{E}$ Blindness, 107(2), 131-142.

Rose, G. (1997). Situating knowledges: Positionality, reflexivities, and other tactics. Progress in Human Geography, 21(3), 305-320.

Smith, B., \& Sparkes, A.C. (2017). Interviews. In B. Smith \& A.C. Sparkes (Eds.), Routledge handbook of qualitative research in sport and exercise (pp.103-123). London, UK: Routledge.

Smith, J.A. (2017). Interpretative phenomenological analysis. In B. Smith \& A.C. Sparkes (Eds.), Routledge handbook of qualitative research in sport and exercise (pp.219-229). London, UK: Routledge.

Smith, J.A., Flowers, P., \& Larkin, M. (2013). Interpretative phenomenological analysis: Theory, method, and research. London, England, Sage.

Smith, J.A., \& Osborn, M. (2008). Interpretative phenomenological analysis. In J.A. Smith (Ed.), Qualitative psychology: A practical guide to research methods (pp.54-80). London, UK: Sage.

Spencer, R.A., Rehman, L., \& Kirk, S. (2015). Understanding gender norms, nutrition, and physical activity in adolescent girls: A scoping review. International Journal of Behavioral Nutrition and Physical Activity, 12(6), 110.

Spencer-Cavaliere, N., \& Watkinson, E.J. (2010). Inclusion understood from the perspectives of children with disability. Adapted Physical Activity Quarterly, 27(4), 275-293. doi:10.1123/apaq.27.4.275

US Department of Health and Human Services (2008). Physical activity guidelines for Americas. Hyattsville, MD: Author.

Walker, S., Reid, S., \& Priest, H. (2013). Use of reflexivity in a mixed-methods study. Nurse Researcher, 20(3), 3843. doi:10.7748/nr2013.01.20.3.38.c9496

Ward, S., Fansworth, C., Babkes-Stellino, M., \& Perrett, J. (2011). Parental influences and the attraction to physical activity for youths who are visually impaired at a residential-day school. Journal of Visual Impairment $\mathcal{E}$ Blindness, 101(6), 339-350.

Williams, G., Aggio, D., Stubbs, B., Pardhan, S., Gardner, B., \& Smith, L. (2018). Physical activity levels in children with sensory problems: Cross-sectional analyses from the Millennium Cohort Study. Disability $\mathcal{E}$ Health Journal, 11(1), 58-61. doi:10.1016/j.dhjo.2017.07.002

Wrzesinska, M., Lipert, A., Urzedowicz, B., \& Pawlicki, L. (2018). Self-reported physical activity using International Physical Activity Questionnaire in adolescents and young adults with visual impairment. Disability E Health Journal, 11(1), 20-30. doi:10.1016/j.dhjo.2017.05.001

Yardley, L. (2000). Dilemmas in qualitative health research. Psychology E Health, 15(2), 215-228.

(C) 2018 by the authors. Submitted for possible open access publication under the terms and conditions of the Creative Commons Attribution (CC BY) license (http://creativecommons.org/licenses/by/4.0/). 